\title{
Prognostic Value of Soluble Intercellular Adhesion Molecule-1 (s-ICAM-1) in HIV-Infected Children
}

\author{
E. GADDI, $*$ S. LAUCELLA, $\dagger$ J. BALBARYSKI, $*$ C. CANTISANO, $*$ G. BARBONI, $*$ M. CANDI* \\ \& V. GIRAUDI* \\ *División Inmunología, Hospital 'Dr Pedro de Elizalde', Buenos Aires, Argentina; † Instituto Nacional de Parasitología, 'Dr Mario Fatala Chabén', \\ Buenos Aires, Argentina
}

(Received 19 May 2000; Accepted in revised form 17 August 2000)

Gaddi E, Laucella S, Balbaryski J, Cantisano C, Barboni G, Candi M, Giraudi V. Prognostic Value of Soluble Intercellular Adhesion Molecule-1 (s-ICAM-1) in HIV-Infected Children. Scand J Immunol 2000;52:628-633

Central events in the host defence system and immune-mediated damage are tightly regulated by cell adhesion molecules. Sera from 28 human immunodeficiency virus (HIV)-1 infected children divided into groups according to disease severity, six seroreverting (SR) children and 25 healthy controls were studied to detect the presence of soluble intercellular adhesion molecule-1 (s-ICAM-1). Soluble ICAM-1 levels were found to be significantly increased in HIV-infected children in comparison with SR children or healthy controls. Levels of soluble ICAM-1 were higher in patients with severe forms of HIV-infection than in those with a milder form of the disease. Significant differences in titers of s-ICAM-1 were recorded between SR children and HIV-infected children with mild disease or healthy controls. There was a significant correlation between s-ICAM-1 levels and the concentrations of beta 2 microglobulin $(\beta 2 \mathrm{~m})$ and, to a lesser extend, immunoglobulin A levels (IgA). Soluble ICAM-1 levels didn't change considerably in HIV-infected children in stable clinical conditions, independently of their clinical stage of the disease, during a follow-up period of 9-12 months. Conversely, s-ICAM-1 levels increased simultaneously with the appearance of new welldefined clinical disorders or decreased during the improvement of clinical conditions. A significant negative correlation was recorded between the titers of the s-ICAM-1 and the CD4 ${ }^{+}$T-cell levels. These results suggest that the s-ICAM-1 might be another useful tool to evaluate disease progression.

Dr E. Gaddi, Desaguadero 2439 (1417), Buenos Aires, Argentina. E-mail: vgiradi@intramed.net.ar

\section{INTRODUCTION}

The intercellular adhesion molecule 1 (ICAM-1), a member of the immunoglobulin superfamily, is expressed on endothelial cells, some epithelial cells, and is present in an intracellular pool in monocytes [1-3]. Activation of lymphocytes results in an increase in ICAM-1 on $\mathrm{T}$ and $\mathrm{B}$ lymphocytes [4]. Treatment of fibroblasts and endothelial cells with inflammatory mediators such as interleukin (IL)-1, tumour necrosis factor (TNF)- $\alpha$, interferon (IFN)- $\gamma$ and lipopolysaccharide results in a dramatic up-regulation of ICAM-1 on the surface of these cells [5]. During immune and inflammatory responses ICAM-1 promotes a leukocyte adhesion by binding to its ligands the leukocyte-function associated antigen-1 (LFA-1), macrophage-1 antigen (MAC-1) and CD43 [6-8].

ICAM-1 is not only present in a membrane-bound, but also in a soluble form which contains all five extracellular domains of membrane-bound ICAM-1 [9]. Soluble ICAM-1 (s-ICAM-1) may thus result from a proteolytic cleavage of cell-bound ICAM-1 close to the cell membrane.

In vitro stimulation of human umbilical vein endothelial cells with cytokines not only increases the cell membrane expression of ICAM-1 but also results in the release of sICAM-1, which increases in parallel with the ICAM-1 cellsurface expression [10]. The release of s-ICAM-1 is not restricted to endothelial cells of different vascular beds, but has 
Table 1. Clinical characterization of HIV-infected children

\begin{tabular}{|c|c|c|c|c|c|}
\hline Patient & $\begin{array}{c}\text { Age } \\
\text { (years) }\end{array}$ & Sex & $\begin{array}{l}\text { Disease } \\
\text { category }\end{array}$ & Clinical conditions & $\begin{array}{c}\text { Antiretroviral } \\
\text { therapy }\end{array}$ \\
\hline 1 & 6 & M & MD & no symptoms & - \\
\hline 2 & 2 & M & MD & no symptoms & - \\
\hline 3 & 8 & $\mathrm{~F}$ & MD & no symptoms & - \\
\hline 4 & 1 & M & MD & no symptoms & - \\
\hline 5 & 6 & $\mathrm{~F}$ & MD & no symptoms & - \\
\hline 6 & 2 & M & MD & Diarrhoea & - \\
\hline 7 & 5 & $\mathrm{~F}$ & MD & lymphadenopathy & AZT \\
\hline 8 & 2 & $\mathrm{~F}$ & MD & lymphadenopathy & AZT \\
\hline 9 & 4 & $\mathrm{~F}$ & $\mathrm{MD}$ & no symptoms & AZT \\
\hline 10 & 1 & $\mathrm{~F}$ & $\mathrm{MD}$ & asthma, diarrhoea & AZT \\
\hline 11 & 2 & M & MD & no symptoms & AZT \\
\hline 12 & 7 & M & MD & no symptoms & - \\
\hline 13 & 7 & $\mathrm{~F}$ & MD & no symptoms & $\mathrm{AZT}$ \\
\hline 14 & 7 & $\mathrm{~F}$ & MD & flu & nevirapine, ddC, nelfinavir \\
\hline 15 & 10 & M & MD & no symptoms & $\begin{array}{l}\mathrm{d} 4 \mathrm{~T} \text {, ritonavir, } \\
\mathrm{ddC}\end{array}$ \\
\hline 16 & 9 & M & MD & no symptoms & ddC, nelfinavir, nevirapine \\
\hline 17 & 1 & $\mathrm{~F}$ & MD & no symptoms & AZT, ddI, nevirapine \\
\hline 18 & 7 & M & MD & no symptoms & $\mathrm{AZT}$ \\
\hline 19 & 2 & M & SD & hepatomegaly & AZT \\
\hline 20 & 9 & M & SD & $\begin{array}{l}\text { undernourishment, } \\
\text { candidiasis }\end{array}$ & AZT \\
\hline 21 & 3 & M & SD & pneumonia & AZT \\
\hline 22 & 3 & $\mathrm{~F}$ & SD & undernourishment, LIP & AZT \\
\hline 23 & 5 & $\mathrm{~F}$ & $\mathrm{SD}$ & $\begin{array}{l}\text { pneumonia, } \\
\text { Herpes zoster, } \\
\text { undernourishment }\end{array}$ & AZT \\
\hline 24 & 1 & $\mathrm{~F}$ & SD & Chronic Hepatitis & $\mathrm{AZT}, \mathrm{ddI}$ \\
\hline 25 & 2 & M & SD & $\begin{array}{l}\text { disseminated bacillus } \\
\text { Calmette Guerin } \\
\text { infection }\end{array}$ & AZT, ddI \\
\hline 26 & 10 & M & SD & Cryptosporidiosis & ritonavir, indinavir \\
\hline 27 & 7 & M & SD & microangiopathy & $\begin{array}{l}\text { AZT, ddI, } \\
\text { indinavir, } \\
\text { ritonavir }\end{array}$ \\
\hline 28 & 7 & $\mathrm{~F}$ & SD & $\begin{array}{l}\text { undernourishment, } \\
\text { Mycobacterium avium }\end{array}$ & AZT, ddI, indinavir, efavirenz \\
\hline
\end{tabular}

F, female; M, male; MD, mild disease; SD, severe disease; AZT, zidovudine; ddI, didanosine, ddC, dideoxycytidine; $\mathrm{d} 4 \mathrm{~T}$, stavudine.

also been reported to occur in vitro in human peripheral blood mononuclear cells (PBMC) [9] and various types of human nonhaematopoietic cells, such as synovial cells [11], hepatocytes [12], and several carcinoma cells [13], as well as melanoma cells [14].

Comparison of levels of specific s-CAMs might provide a better understanding of a particular pathology. While s-ICAM-1 can be detected in the circulation of normal human individuals [9], there is now quite a large number of studies to demonstrate that levels of s-ICAM-1 in various human body fluids are elevated in a wide variety of inflammatory and infectious diseases, as well as in cancers [15-21].

Several studies have reported changes in s-ICAM-1 in adult HIV-1 infected patients [22-25] but, to the author's knowledge, there have been no reports in children.

In the study presented herein, s-ICAM-1 levels were measured in HIV-infected children with different degrees of disease evolution. 
The s-ICAM-1 levels were associated with parameters of immune activation and disease progression in order to determine if s-ICAM-1 could be of any predictive value in the course of the disease.

\section{PATIENTS AND METHODS}

Study population. Serum samples were collected from paediatric HIV-1 infected patients treated at the authors' College Hospital. The group studied comprised 28 HIV-1 infected patients (13 males, 15 females, aged 9 months to 7 years) and six children born from HIV-infected mothers that have later become HIV-antibody negative (SR children aged 6-11 months). HIV-infection was confirmed by ELISA and Western blot analysis; vertical transmission was observed in all subjects. Patients were selected on the basis of their clinical status according to the CDC 1994 paediatric classification [26]. HIV-1 infected children were divided into the following groups: children with nonsymptomatic or mildly symptomatic disease (category MD, $n=18$ ) and children with severely symptomatic disease (category SD, $n=10$ ). All symptomatic HIV-infected children were under antiretroviral therapy with reverse transcriptase inhibitors and/or protease inhibitors. The clinical features of HIV-infected children studied are shown in Table 1. Control samples were obtained from 25 HIV-1 seronegative healthy children, aged 1-8 years, among the population coming to the hospital for vaccination. Informed consent was obtained from the parents of all children included in the study.

Determinations of levels of $s-I C A M-1, I g A$ and $\beta 2 \mathrm{~m}$. Serum levels of s-ICAM-1 were measured by a two site enzyme-linked immunosorbent assay kit (R \& D System, Minneapolis, USA), according to the manufacturers instructions. Serum IgA levels were evaluated by nephelometry (QM 300, Sanofi Pasteur, Marne la Coquette, France), whereas $\beta 2 \mathrm{~m}$ concentrations were determined by a radial immunodiffusion assay (The Binding Site, Birmingham, UK).

CD4+ T-cell count in HIV-infected children. Relative values of $\mathrm{CD}^{+}$and $\mathrm{CD}^{+}$were evaluated by double-labelling studies. One hundred $\mu l$ of heparinezed whole blood were incubated with CD4-PE and CD3-fluorescein isothiocyanate (FITC) or CD8-PE and CD3-FITC for $30 \mathrm{~min}$ at room temperature. Staining with nonrelated isotype controls showed the nonspecific fluorescence. All monoclonal antibodies (MoAbs) were obtained from Becton Dickinson (Mountain View, CA, USA). After incubation the samples were lysed with FASCS lysing solution. Cells were fixed with $1 \%$ paraformaldehyde, $1 \%$ sodium cacodylate- $\mathrm{NaCl}$ for at least $15 \mathrm{~min}$ and 10000 cells per tube were analyzed with a Becton-Dickinson FACScan flow cytometer (Becton-Dickinson). Data were analyzed by using the Simulset Software (Becton Dickinson). The percentage of $\mathrm{CD}^{+} \mathrm{CD}^{+}$or $\mathrm{CD}^{+} \mathrm{CD}^{+}{ }^{+} \mathrm{T}$-cells was determined in the patients studied.

Statistical analysis. The Mann-Whitney $U$-test was used to compare levels of s-ICAM-1, IgA and $\beta 2 \mathrm{~m}$ in the different groups evaluated. A correlation analysis was obtained by Spearman rank method. $P<0.05$ was considered statistically significant.

\section{RESULTS}

Levels of s-ICAM-1 were measured in sera from HIV-1 infected children, either with a mild or a severe disease, and compared with levels either in aged-matched noninfected children, or SR children.

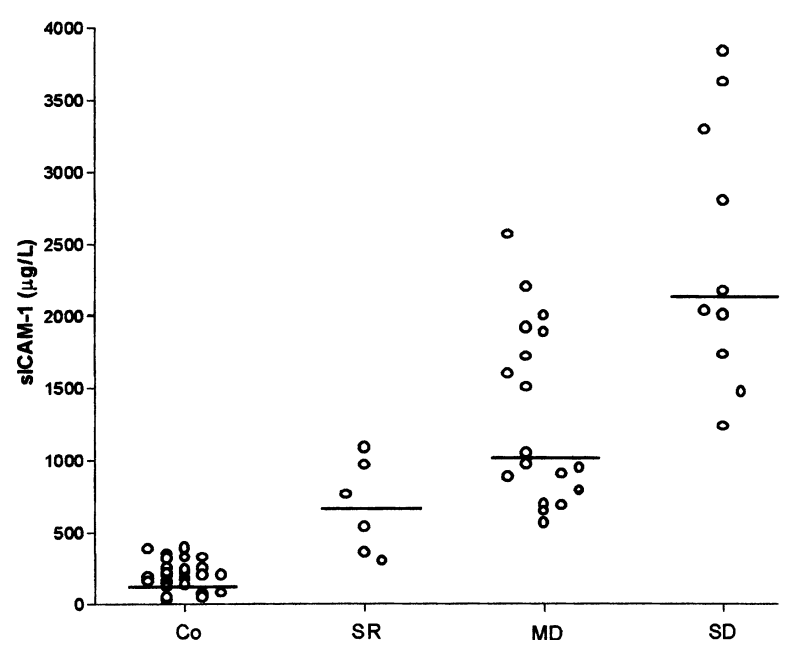

Fig. 1. Levels of s-ICAM-1 in sera from children with mildly symptomatic (MD, $n=18$ ), or severely symptomatic ( $\mathrm{SD}, n=10$ ) HIV-infection. The levels of s-ICAM-1 were determined in sera from HIV-infected children, seroreverting (SR) children $(n=6$, see Patients and Methods) or noninfected, age-matched controls $(\mathrm{C} 0, n=25)$. Each point represents one patient; the groups median are shown as well. Statistical analysis was performed using the Mann-Whitney $U$-test. Levels of s-ICAM-1 were higher in HIV-infected children compared with SR children or healthy controls $(P<0.05)$. s-ICAM-1 levels were significantly higher in SD compared with MD $(P<0.05)$ and SR $(P<0.05)$. Differences in titers of s-ICAM-1 between SR children and MD $(P<0.05)$ or healthy controls $(P<0.01)$ were statistically significant.

Soluble ICAM-1 levels were found significantly increased in HIV-infected children (median s-ICAM-1 $=1162 \mu \mathrm{g} / \mathrm{l}$ ), in comparison with healthy controls (median s-ICAM$1=200.5 \mu \mathrm{g} / \mathrm{L} ; \quad P<0.0001$ ) or $\quad \mathrm{SR}$ children (median s-ICAM-1 $=706 \mu \mathrm{g} / \mathrm{L} ; P<0.05)$. Levels of s-ICAM-1 were higher in patients with severe forms of HIV-infection than in a milder form of the disease (Fig. 1). Significant differences in titers of s-ICAM-1 were recorded between SR children and HIVinfected children with mild disease or healthy controls (Fig. 1).

The relationship between the levels of s-ICAM-1 and parameters of immune activation has also been examined. HIV-infected children showed significantly higher $(P<0.05)$ $\operatorname{IgA}($ median $=1190 \mathrm{mg} / \mathrm{l})$ and $\beta 2 \mathrm{~m}($ median $=3.66 \mathrm{mg} / \mathrm{l})$ levels compared with noninfected controls $(\operatorname{IgA}=593 \mathrm{mg} / \mathrm{L}$; $\beta 2 \mathrm{~m}=1,90 \mathrm{mg} / \mathrm{l})$. A significant correlation was found between s-ICAM-1 levels and the concentrations of $\beta 2 \mathrm{~m}(r=0.48$; $P<0.05)$ whereas a low correlation was found with IgA levels $(r=0.35 ; P<0.05)$ (Fig. 2).

In order to evaluate the usefulness of s-ICAM-1 as prognostic indicator, s-ICAM-1 levels were determined in nine HIVinfected children and compared with $\mathrm{CD}^{+}{ }^{+} \mathrm{T}$ cells levels every 3 months during a follow-up period of 9-12 months.

Soluble ICAM-1 levels didn't change considerably in HIVinfected children in stable clinical conditions, independently of their clinical stage of the disease (Fig. 3A and B). In contrast, levels of s-ICAM-1 increased at the same time as the appearance 

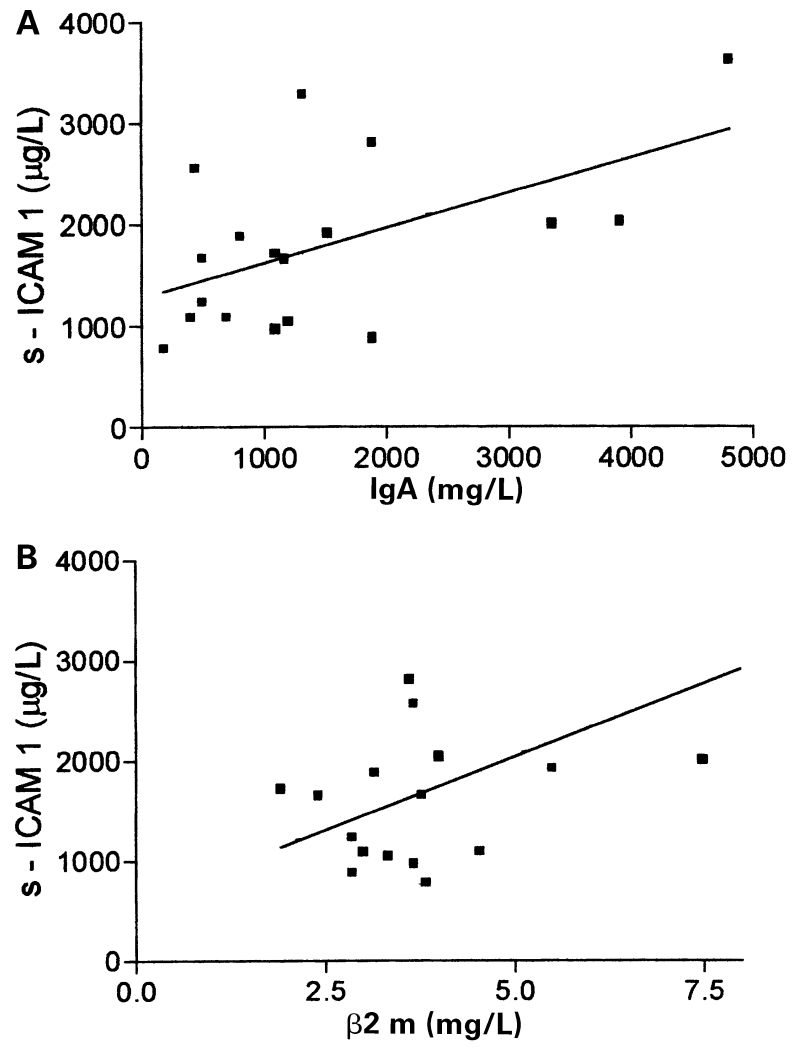

Fig. 2. Correlative analysis of s-ICAM-1, immunoglobulin (Ig)A and beta 2 microglobulin $(\beta 2 \mathrm{~m})$ serum levels. The Spearman rank test was performed to establish the correlation between serum s-ICAM-1, IgA and $\beta 2 \mathrm{~m}$ levels in $28 \mathrm{HIV}-1$ infected children. There was a significant correlation between serum s-ICAM-1 and both $\operatorname{IgA}(r=0.35$; $P<0.05)$ and $\beta 2 \mathrm{~m}(r=0.48 ; P<0.05)$ levels.

of a hepatitis $\mathrm{C}$ infection. Later on, levels of s-ICAM-1 decreased along with disease activity. In the same way, in another case with severely symptomatic disease, s-ICAM-1 levels increased simultaneously with the development of microangiopathy (Fig. 3B). Patients showing an improvement in clinical conditions considerably decreased s-ICAM-1 levels over time (Fig. 3A).
A negative correlation was recorded between the titers of sICAM-1 and CD4 ${ }^{+} \mathrm{T}$ cells levels in HIV-infected children under follow-up $(r=-0.63 ; P<0.001)$.

\section{DISCUSSION}

Data are presented showing that serum levels of s-ICAM-1 are elevated in HIV-1 infected children and correlated with disease severity. These results are in accordance with a previous report showing increased levels of s-ICAM-1 in adult patients with a severe form of HIV-1 infection [27-29]. However, HIVassociated immune activation and the course of infection may differ in HIV-infected children with regard to adults, because most children are infected perinatally, HIV being introduced into a naive and developing immune system. The child immune system is generally less responsive to viruses and shows immunophenotypic evidence of immaturity. Then, information obtained from studies performed in adults cannot be extrapolated to the paediatric population [30].

Soluble forms of CAMs are released into serum, either because of shedding from the endothelial cell surface or differential mRNA splicing to form a truncated, soluble form with noncytoplasmic anchoring sequence [10]. The amounts of soluble vascular cell adhesion molecule-1 (s-VCAM-1), sICAM-1, s-E-selectin and soluble platelet selectin (s-P-selectin) released showed a direct correlation with cell surface expression of these molecules [21,31]. Thus, high levels of s-ICAM-1 recorded in sera from HIV-1 infected children suggest the increased expression of such molecule on the cell surface. Alternatively, s-ICAM-1 might be released from damaged or inflamed tissue [9].

An issue of major importance when determining levels of soluble adhesion molecules is whether or not these soluble adhesion molecules detected are biologically active. Furthermore, there may be a difference in the systemic and local biological activity of shed adhesion molecules.

With regard to the possible physiological roles of circulating adhesion molecules, two major concepts have emerged, which are not mutually exclusive. First, if the shed molecules retain

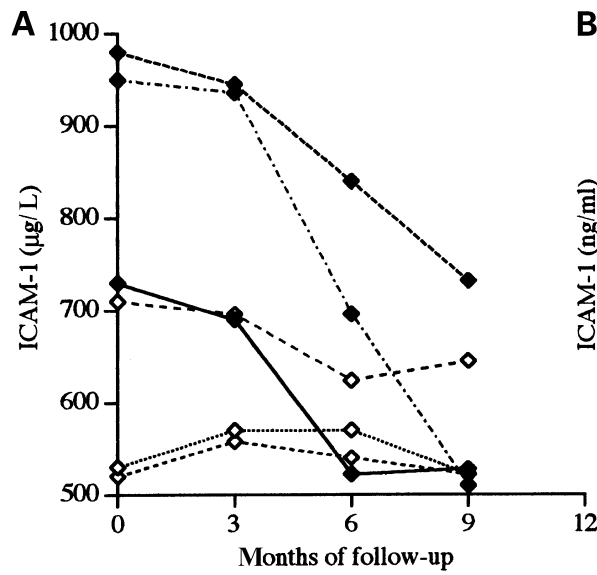

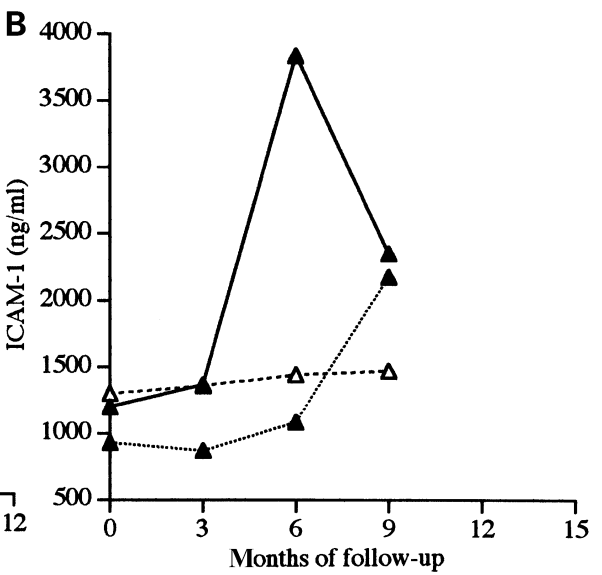

Fig. 3. Fluctuation of the levels of s-ICAM-1 in the clinical course of HIV-infection. Serum levels of s-ICAM-1 were evaluated in six HIVinfected children with mild disease (A) and three children with severe disease (B) every 3 months during a follow-up period of 9-12 months. Open symbols represent HIV-infected children in stable clinical conditions whereas children showing new clinical disorders or health improvement during the time of follow-up are represented by the closed symbols. 
their ability to bind their specific ligands on leukocytes, the release of these adhesion molecules may induce a decrease in the potential adhesiveness of leukocytes by competing with the membrane-bound receptors for their ligands. Indeed, it has been suggested that s-ICAM-1 may play a role in downregulating adhesive interactions between the leukocytes and the membrane-bound form of this adhesion molecule [11]. In this context, increased s-ICAM-1 levels in HIV-1 infected patients might have a beneficial effect by regulating adhesion. Secondly, soluble adhesion molecules can act as costimulatory factors, triggering a response in a ligand-bearing cell. s-ICAM-1 has been demonstrated to deliver chemokinetic signals to lymphocytes and to enhance cytokine production and T-cell proliferative responses stimulated by alloantigen in mixed lymphocyte cultures [32]. From a clinical perspective, the issue whether elevated circulating levels of soluble adhesion molecules in pathological inflammatory conditions are either of benefit for, or detrimental to patients, is still open.

ICAM-1 may be relevant in the pathogenesis of HIV-1 infection because it was claimed that the ICAM-1/LFA-1 adhesion pathway might be involved in a HIV-1 cytopathic mechanism of syncytia formation, as well as in the spread of the virus by cell-cell transmission [33-35]. In addition, LFA-1/ ICAM -1 interaction has been reported to be a potent costimulus for antigen-specific activation of resting $\mathrm{T}$ cells and to mediate lymphocyte sequestration in lymphoid tissue [25, 36].

Increased levels of s-ICAM-1 were found in SR children. Considering that the SR children were younger than 1 year, the s-ICAM-1 levels could have been transferred by the placenta from the mother. However, little is known about the clearance of circulating adhesion molecules.

Our findings concerning the correlation between levels of sICAM- 1 and $\beta 2 \mathrm{~m}$, points to a role of s-ICAM- 1 as a marker of immune activation, because $\beta 2 \mathrm{~m}$ appeared to be a wellestablished marker of immune activation in HIV-infection [37-39]. However, the relatively poor correlation observed, in particular with $\operatorname{IgA}$, suggests that the expression of these molecules could be affected by different stimuli.

There are conflicting reports regarding the correlation between ICAM-1 levels and CD4 cell counts in adults [23, 24, 28, 29]. The association between the levels of s-ICAM-1 and $\mathrm{CD} 4^{+}$counts as well as the fact that the s-ICAM- 1 increased along with the appearance of concurrent diseases suggest that sICAM-1 might be a valuable prognostic indicator in confirmed paediatric HIV-infection. Moreover, two out of the three children with severe disease whose s-ICAM-1 levels were evaluated during a follow-up period, died at the end of this study. Conversely, three patients showing improving clinical conditions during the follow-up showed decreased s-ICAM-1 levels.

It has been shown that the expression of ICAM-1 was dramatically reduced during antiretroviral therapy [25] suggesting that the ICAM-1 levels are increased because of the HIV infection. Likewise, the three children showing a striking decrease in s-ICAM-1 during follow-up were under treatment with three different antiretroviral drugs. However, increased sICAM-1 levels recorded in SR children suggests that the sICAM-1 could be useful in confirmed HIV-infection.

Both adult and paediatric studies have during the last 5 years clearly demonstrated the prognostic significance of plasma RNA and CD4 [39-42] levels in the course of HIV-infection. Indeed, these markers have become the cornerstones of our understanding of HIV pathogenesis and the basis of current treatment strategies. However, the use of s-ICAM-1, might be another useful tool to evaluate disease progression.

\section{ACKNOWLEDGMENTS}

This work was supported by Departamento de Salud, Gobierno de la Ciudad de Buenos Aires, and Consejo Nacional de Investigaciones Científicas y Tecnológicas (CONICET), Argentina.

\section{REFERENCES}

1 Dustin ML, Springer TA. Role of lymphocyte adhesion receptors in transient interactions and cell locomotion. Annu Rev Immunol 1991;9:27-66.

2 Dougherty G, Murdoch S, Hogg N. The function of human intercellular adhesion molecule-1 (ICAM-1) in the generation of an immune response. Eur J Immunol 1988;18:35-9.

3 Miller JM, Knorr R, Ferrone $\mathrm{M}$ et al. Intercellular adhesion molecule-1 dimerization and its consequences for adhesion mediated by lymphocytes function associated-1. J Exp Med 1995; 182:1231-41.

4 Dustin ML, Rothlein R, Bhan AK, Dinarello CA, Springer TA. Induction by IL-1 and Interferon $\gamma$ : Tissue distribution, biochemistry and function of a natural adherence molecule (ICAM-1). J Immunol 1986;137:245-54.

5 Dustin ML, Singer KH, Tuck DT, Springer TA. Adhesion of T lymphoblasts to epidermal keratinocytes is regulated by interferon gamma and is mediated by intercellular adhesion molecule- 1 (ICAM-1). J Exp Med 1988;167:1323-40.

6 Marlin D, Springer TA. Purified intercellular adhesion molecule-1 (ICAM-1) is a ligand for lymphocyte function associated antigen 1 (LFA-1). Cell 1987;51:813-9.

7 Diamond MS, Staunton DE, De Fougerolles AR et al. ICAM-1 (CD54): a counter-receptor for Mac-1 (CD11b/CD18). J Cell Biol 1990;111:3129-39.

8 Rosenstein Y, Park JK, Hahn WC, Rosen FS, Bierer BE, Burakoff SJ. CD43, a molecule defective in Wiskott-Aldrich syndrome, binds ICAM-1. Nature 1991;354:233-5.

9 Rothlein R, Mainolfi E, Czajkowski M, Marlin S. A form of circulating ICAM-1 in human serum. J Immunol 1991;147:37884003.

10 Piggot R, Dillon P, Hemingway I, Gearing A. Soluble forms of ESelectin, ICAM-1 and VCAM-1 are present in the supernatants of cytokine activated cultured endothelial cells. Biochem Biophys Res Commun 1992;187:584-9.

11 Shingu M, Hashimoto M, Ezaki I, Nobunaga M. Effect of cytokineinduced soluble ICAM-1 from human synovial cells on synovial cell-lymphocyte adhesion. Clin Exp Immunol 1998;98:46-51.

12 Thomson AW, Satoh S, Nussler AK et al. Circulating intercellular adhesion molecule-1 (ICAM-1) in autoimmune liver disease and 
evidence for the production of ICAM-1 by cytokine-stimulated human hepatocytes. Clin Exp Immunol 1994;95:83-90.

13 Hansen AB, Lillevang ST, Andersen CB. Stimulation of intercellular adhesion molecule-1 (ICAM-1) antigen expression and shedding by interferon-gamma and phorbol ester in human renal carcinoma cell cultures: relation to peripheral blood mononuclear cell adhesion. Urol Res 1994;22:85-91.

14 Giavazzi R, Chirivi RGS, Garofalo A et al. Soluble intercellular adhesion molecule- 1 is released by human melanoma cells and is associated with tumor growth in nude mice. Cancer Res 1992;52:2628-30.

15 Hansen AB, Bouchelouche PN, Lillevang ST, Andersen CB. Interferon gamma increases cellular calcium ion concentration and inositol 1,4,5-triphosphate formation in human renal carcinoma cells: relation to ICAM-1 antigen expression. $\mathrm{Br} \mathrm{J}$ Cancer 1994;69:291-8.

16 Nielsen OH, Langholz E, Hendel J, Brynskov J. Circulating soluble intercellular adhesion molecule-1 (sICAM-1) in acitve inflammatory bowel disease. Digest Dis Sci 1994;39:1918-23.

17 Nouri-Aria KT, Koskinas J, Tibbs CJ, Portmann BC, Williams R. Serum intercellular adhesion molecule-1 levels in chronic hepatitis C. Gut 1995;36:599-603.

18 Laucella SA, de Titto EH, Segura EL, Orn A, Rottenberg ME. Soluble cell adhesion molecules in human Chagas disease: association with disease severity and stage of infection. Am J Trop Med \& Hyg 1996;55:629-34.

19 Laucella SA, Gaddi E, Balbaryski J, Giraudi V, Cuttica RJ. Soluble intercellular adhesion molecule-1 in paediatric connective tissue diseases. Acta Paediatr 1999;88:399-403.

20 Laucella S, Salcedo R, Castaños-Velez E et al. Increased expression and secretion of ICAM-1 during experimental infection with Trypanosoma cruzi. Paras Immunol 1996;18:227-39.

21 Laucella SA, Segura EL, Riarte A, Sosa Estani S. Soluble Platelet Selectin (S-P-Selectin) and Soluble Vascular Adhesion Molecule-1 (S-VCAM) decrease during treatment with benznidazole of children in indeterminate phase of Chagas Disease. Clin Exp Immunol 1999;118:423-7.

22 Most J, Zangerle R, Herold M et al. Elevated concentrations of circulating intercellular adhesion molecule 1 (ICAM-1) in HIV infection. J Acquire Immune Defic Syndr 1993;6:221-6.

23 Sipsas N, Sfikakis PP, Sfikakis P, Choremi H, Kordissis T. Serum concentrations of soluble intercellular adhesion molecule-1 and progress towards disease in patients infected with HIV. J Infect 1994;29:271-82.

24 Norday L, Aukrust P, Muller F, Froland S. Abnormal levels of circulating adhesion molecules in HIV-1 infection with characteristic alterations in opportunistic infections. Clin Immunol Immunopathol 1996;81:16-21.

25 Bucy RP, Hockett RD, Derdeyn CA et al. Initial increase in blood $\mathrm{CD}^{+}$lymphocytes after HIV antiretroviral therapy reflects redistribution from lymphoid tissues. J Clin Invest 1999; 103:1391-8.

26 CDC. Revised classification system for human immunodeficiency virus infection in children less than 13 years of age. MMWR 1994; 43:1-10.

27 Diez Ruiz A, Kaiser G, Jager H et al. Increased levels of serum intercellular adhesion molecule 1 in HIV infection are related to immune activation. Int Arch Allergy Immunol 1993;102:56-60.

28 Gattegno L, Bentata Peyssare M, Granowski S, Chauche K, Ferriere F. Elevated concentrations of circulating intercellular adhesion molecule 1 (ICAM -1) and of vascular cell adhesion molecule 1 (VCAM -1) in HIV infection. Cell Adhes Commun 1995;3:179-85.

29 Galea P, Vermount C, Le Contel C, Wydenes J, Chermann J. Circulating cell adhesion molecules in HIV-1 infected patients as indicator markers for AIDS progression. Res Immunol 1997;148:109-17.

30 Plaeger-Marshall S, Isacescu V, Rourke S, Bertoll J, Bryson Y, Stheim R. T cell activation in pediatric AIDS pathogenesis: threecolor immunophenotyping. Clin Immunol Immunopathol 1994; 71:19-26.

31 Lang T, Krams S, Villanueva J, Cox K, So S, Martinez D. Differential patterns of circulating intercellular adhesion molecule-1 (cICAM-1) and vascular adhesion molecule-1 (cVCAM-1) during liver allograft rejection. Transplantation 1995;59:584-9.

32 McCabe SM, Riddle L, Nakamura GR, Prashad H et al. sICAM-1 enhances cytokine production stimulated by alloantigen. Cell Immunol 1993;150:364-75.

33 Berman P, Nakamura G. Adhesion mediated by intercellular adhesion molecule 1 attenuates the potency of antibodies that blocks HIV-1 gp 160- dependent syncytium formation. AIDS Res Human Ret 1994;10:585-93.

34 Fauci A, Butini L, DeFougerolles A et al. Intercellular adhesion molecules ICAM-1, ICAM-2, ICAM-3 function as counter receptors for lymphocyte function-associated molecule 1 in human immunodeficiency virus-mediated syncytia formation. Eur J Immunol 1994;24:2191-5.

35 Golding H, Gruber M, Webb D, Gerrard T, Mostowski H, Vujcic L. Re-evaluation of the involvement of the adhesion molecules ICAM/LFA-1 in syncytia formation of HIV-1 infected subclones of a CEM T-cell leukemia line. AIDS Res Human Ret 1991;7: 45-53.

36 Shaw S, Van Seventer G, Shimizu Y, Horgan K. The LFA-1 ligand ICAM-1 provide an important costimulary signal for T-cell receptor mediated activation of resting T-cells. J Immunol 1990;144:457986.

37 Fahey J, Taylor J, Detels R et al. The prognostic value of cellular and serologic markers in infection with human immunodeficiency virus type 1. N Engl J Med 1990;322:166-72.

38 Fuchs D, Hausen A, Reibnegger G, Werner E, Werner-Feldmayer G, Watcher H. $\beta 2$ microglobulin and immune activation. Clin Chem 1989;35:2158.

39 Ellaurie M, Rubinstein A. $\beta 2$ microglobulin concentrations in pediatric human immunodeficiency virus infection. Pediatr Infect Dis J 1990;9:807-9.

40 Hughes MD, Johnson VA, Hirsch M et al. Monitoring plasma HIV1 RNA levels in addition to $\mathrm{CD}^{+}{ }^{+}$lymphocyte count improves assessment of antirretroviral therapeutic response. Ann Int Med 1997;126:929-38.

41 Ho DD, Neumann AU, Parelson AS, Chen W, Leonard JM, Markowitz M. Rapid turnover of plasma virions and CD4 lymphocytes in HIV-infection. Nat 1995;373:123-6.

42 Schnittman SM, Greenhouse JJ, Psallidopoulos MC, Baseler M, Salzman N, Fauci A. Increasing viral burden in $\mathrm{CD}^{+}{ }^{+} \mathrm{T}$ cells from patients with human immunodeficiency virus (HIV) infection reflects rapidly progressive immunosupression and clinical disease. Ann Int Med 1990;113:438-43.

43 O'Brien WA, Hartigan PM, Martin D et al. Changes in plasma HIV1 RNA and CD4 lymphocytes counts and the risk of progression to AIDS. N Engl J Med 1996;334:426-31. 